Tempo Social; Rev. Sociol. USP, S. Paulo, 13(1): 143-158, maio de 2001.

\title{
A mestiçagem e seus contrários etnicidade e nacionalidade no Brasil contemporâneo
}

\author{
SÉRGIO COSTA \\ "No meu país o preconceito é eficaz. \\ Te cumprimentam na frente, te dão um tiro por trás” \\ (Mano Brown \& Ice Blue, Rap Racistas Otários)
}

RESUMO: A imagem de uma brasilidade mestiça, culturalmente assimilacionista e politicamente integradora, conforma o núcleo da ideologia que configura a nação brasileira a partir das primeiras décadas do séc. XX. O elogio do hibridismo constitui, assim, a forma de superação dos biologismos racistas predominantes nos debates político e intelectual de até então. Tal modelo de nacionalidade, contudo, perde crescentemente, ao longo da democratização, sua força legitimadora. Muitas das manifestações culturais recentes assim como alguns dos atores sociais importantes no Brasil contemporâneo buscam a identificação étnica que os distinga da nação que assimilou em seu bojo as diferenças culturais. Tratam, dessa forma, de exprimir o descontetamento com as desigualdades estruturais associadas ao processo de construção ideológica da nação mestiça. $O$ artigo descreve tais processos de etnização e discute as conseqüências destes para a construção democrática.

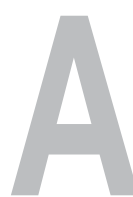

quilo que alguns atores sociais já sabiam pela experiência histórica, só recentemente foi demonstrado de forma convincente pelas ciências sociais: as nações contemporâneas não conformam coletivos orgânicos de indivíduos associados voluntariamente por vínculos essenciais comuns. Trata-se, ao contrário, de "comunidades imaginadas", construídas de forma mais ou menos contingente, tanto através da ação política e bélica, quanto por meio da narrativa capaz de cunhar, no plano discursivo, a identidade comum. Foi Homi Bhabha (1990) o autor a caracterizar de forma mais completa e adequada o momento narrativo de construção das nações, mostrando como este encontra-se assente na tensão

Professor de sociologia na Universidade Livre de Berlim

PALAVRAS-CHAVE: etnicidade, mestiçagem, nacionalidade, Brasil. 
Versões anteriores desse artigo foram apresentadas no VI Congresso Luso-AfroBrasileiro de Ciências Sociais, no Porto, e em conferências na Universidade Livre de Berlim, na Universidade de Leipzig, na Universidade Federal de Santa Catarina e na Universidade de Fortaleza. Registro o agradecimento pelas importantes críticas e sugestões recebidas nessas ocasiões.

Diferentes autores observam um movimento semelhante no processo de formação nacional em outros contextos na América Latina. Isto é, historicamente a avaliação positiva da mistura de fenótipos humanos e das heranças culturais correspondentes substitui a subordinação adscritiva dos não-brancos. Recentemente, denuncia-se a própria mestiçagem como forma de exclusão social e cultural, na medida em que esta de fato justifica e legitima a posição inferior dos não-brancos (cf. Gabbert, 1993, sobre o México, StröbeleGregor, 1993, sobre a Bolívia, e Speck, 1999 para o Peru e o Brasil). entre uma estratégia pedagógica e outra performativa. A ação pedagógica toma o povo como objeto dos discursos nacionais que reafirmam a origem comum e os laços essenciais que unem os "compatriotas". Através da ação performativa, promove-se a permanente reinterpretação dos símbolos nacionais que faz do povo sujeito da reposição viva e permanente do desígnio comum. Essa dupla operação discursiva confere realidade à comunidade nacional imaginada, estabelecendo, ao mesmo tempo, seu ser e seu provir, a essência que a ela vincula um povo, uma cultura e um território e o movimento, a transformação (cf. Bhabha, 1990, p. 297).

A nação brasileira também tem o seu processo de construção narrativa - sua dimensão ideológica - e é dele que trata este texto. Procura-se demonstrar como o período que vai aproximadamente do final dos anos 30 até os anos 70 é marcado no Brasil pela dominância de uma certa ideologia, chamada aqui de ideologia da mestiçagem. A partir do final dos anos 70, esta ideologia vai, por diversas razões, perdendo paulatinamente sua força integradora.

De saída, deve-se esclarecer que a idéia de mestiçagem introduzida aqui em nada se confunde com o cruzamento biológico de diferentes fenótipos humanos, processo que não apresenta per se qualquer relevância político-sociológica. Interessa-nos a transformação da mestiçagem na ideologia de Estado que baseará a construção nacional a partir dos anos 30. Trata-se de uma visão de mundo que reinventa o país, na medida em que revela a possibilidade de convivência dos diferentes grupos socioculturais então residentes dentro das fronteiras político-geográficas brasileiras. Deve-se lembrar que até as primeiras décadas do séc. XX uma questão polarizava o debate político brasileiro, a saber, até que ponto seria possível constituir uma nação unitária e progressista nos trópicos, partindo-se de grupos populacionais tão heterogêneos quanto exescravos e seus descendentes, os diversos povos indígenas, imigrantes de diferentes origens e "mestiços" de todos os tons ${ }^{1}$.

Uma tal ideologia da mestiçagem encontra em Gilberto Freyre sua melhor expressão intelectual, no plano político é Vargas quem confere à mestiçagem rasgos de ideologia estatal da qual os próximos governantes até os governos militares não abririam mão.

Trata-se inicialmente de algumas das posições presentes no debate racial brasileiro na virada para o séc. XX, procurando-se mostrar como a ideologia da mestiçagem, na medida em que oferece uma resposta clara aos problemas levantados no âmbito de tal discussão, a dissolve. Passa-se a seguir à apresentação dos traços constitutivos fundamentais da ideologia da mestiçagem e daí à apresentação de desenvolvimentos recentes que trazem à tona os limites de tal estratégia de legitimação. Finalmente, esboça-se alguns dos problemas de natureza política e cultural colocados pelo esgotamento da ideologia da mestiçagem. 


\section{Debate racial no advento do séc. XX}

Diversos trabalhos recentes operam a reconstrução do debate racial ocorrido no Brasil desde fins do séc. XIX e nas primeiras décadas do séc. XX de forma exaustiva e competente (cf. Schwarcz, 1993; Munanga, 1999; Hofbauer, 1995; entre outros). Ainda que distintos em suas ênfases e avaliações, tais trabalhos convergem ao caracterizar o debate racial da virada do século como expressão do ceticismo então dominante quanto às possibilidades de se construir uma nação progressista nos trópicos, uma vez que a população era constituída em grande medida de negros e mestiços.

O legista baiano Nina Rodrigues representa talvez o primeiro brasileiro a se ocupar de forma sistemática e, segundo os critérios então vigentes, cientificamente com aquilo que se definia como composição racial da população brasileira ${ }^{2}$. Apoiando-se nas teses e nos métodos dominantes no debate racial europeu, com ênfase nas contribuições francesas do séc. XIX, Nina Rodrigues investiga grupos populacionais negros da região de Salvador, concluindo que estes apresentam, ao lado de uma vigorosa produção cultural, uma iniludível inferioridade intelectual que impediria sua integração na nação em igualdade de condições com brancos (cf. Rodrigues, 1935). Segundo o autor, os negros possuiriam uma consciência subdesenvolvida, não estando em condições de assumir todos os direitos e deveres que cabiam aos demais cidadãos. Nesse sentido, o primeiro código penal republicano, ao não distinguir os cidadãos conforme a cor de sua pele, torna-se alvo da dura crítica de Nina Rodrigues. Seria o mesmo, segundo ele, que punir menores de idade porque ainda não cresceram ou loucos por serem mentalmente perturbados. Nina Rodrigues condena com igual veemência o cruzamento entre grupos de cor distintos, do qual decorreria irremediavelmente a degradação da "raça brasileira" (cf. Hofbauer, 1995, p. 84s).

É exatamente na avaliação do que se chamava à época cruzamentos inter-raciais que Silvio Romero e Oliveira Vianna se distinguem de Nina Rodrigues. Mesmo partilhando do diagnóstico pessimista do médico baiano quanto à composição racial brasileira, Romero e Vianna apostam na mistura racial como forma de melhorar geneticamente, vale dizer, de branquear, a população. São conhecidas as projeções demográficas de Vianna (1923), segundo as quais as misturas raciais sucessivas levariam ao crescimento permanente do percentual de sangue ariano na população e à conseqüente dominância das características fenotípicas européias.

Uma posição presente nesse debate ainda desconhecida no Brasil é aquela defendida pelo pesquisador racial nazista Heinrich Krieger. Num ensaio publicado em 1940, Krieger busca dar razão a Nina Rodrigues quando este mostra as consequiências deletérias da mistura de raças. Conforme Krieger, os mestiços são degenerados, sem pertença racial definida, enquanto os negros, a despeito de sua inferioridade intelectual, constituíam uma raça pura. $\mathrm{O}$ autor chega mesmo a elogiar a nascente Frente Negra Brasileira, que celebrava, segundo ele, o orgulho racial de um grupo puro, em distinção ao festejamento das misturas raciais já
2 Já se mostrou que as características que compõem a classificação racial em seu sentido biológico não apresentam validade quando aplicada à espécie humana (cf. Alencastro, 1985). Isto é, não se verifica superposição entre os critérios científicos de classificação racial e as características fenotípicas (cor da pele, formato do rosto, tipo de cabelo, etc.) em geral utilizadas nas distinções estabelecidas pelo senso comum. Dessa forma, expressões aqui utilizadas como cruzamento inter-racial visam apenas reproduzir os termos do debate do início do séc. XX e repetem, por isso, as classificações "raciais" de senso comum apoiadas na seleção arbitrária de um conjunto de características fenotípicas. 
${ }^{3} \mathrm{O}$ significado do caso brasileiro para o Terceiro Reich pode ser medido pela posição de Ley, ministro, chefe da Frente de Trabalho e um homens-chave do regime nazista. Ele mostra-se indignado com o fato da Alemanha contar com o mesmo direito de voto na conferência da Organização Internacional do Trabalho realizada em 1933 em Genebra que cabia aos "países semiselvagens de negros" da América Latina. Ao ser indagado por Fischlowitz (1950), presente à conferência, se um país como o Brasil era mesmo adversário que merecesse tamanha ênfase, Ley reage com a afirmação de que o Brasil, com seu programa "absurdo" de mistura de raças atentava contra a evidência objetiva da superioridade ariana.

* A data entre colchetes refere-se à edição original da obra. Ela é indicada na $1^{\mathrm{a}}$ vez que a obra é citada. Nas demais, indica-se somente a edição utilizada pelo autor (N.E.). então dominante. Krieger questiona a qualidade técnica das estatísticas de Oliveira Vianna demonstrando que, a persisitirem os cruzamentos inter-raciais, ter-se-ia no Brasil, ao contrário do gradativo branqueamento prognosticado, um rápido escurecimento da população. Através de uma política conseqüente que fizesse evitar os casamentos inter-raciais poder-se-ia, contudo, conforme Krieger, manter preservado um grupo ariano com as faculdades necessárias para as funções de direção da sociedade, abrindo-se assim as possibilidades para o florescimento de uma nação progressista governada pelos grupos brancos ${ }^{3}$.

A relativização do significado da raça para a constituição de um país moderno nos trópicos seria desenhada pioneiramente por Alberto Torres. Segundo o autor, o subdesenvolvimento brasileiro não deve ser atribuído à inferioridade intelectual de seu povo, ele é produto da inadequadação das instituições políticas, cuja conformação não teria levado em conta as especificidades da sociedade brasileira. Ipsis verbis:

Nenhum dos povos contemporâneos é formado de uma raça homogênea e isto não lhe impediu de formar uma nação, moral, política e socialmente (...) Se os indígenas, os africanos e seus descendentes não puderam 'progredir e aperfeiçoar-se' isto não se deve a qualquer incapacidade inata, mas ao abandono em vida selvagem ou miserável, sem progresso possível (apud Munanga 1999, p. 61).

Uma tal estratégia argumentativa, na qual o peso de determinação da raça desloca-se para as condições estruturais da sociedade, seria retomada mais tarde por Gilberto Freyre. Nesse sentido, o clássico Casa-grande \& senzala (Freyre, [1933]*1999), ao descrever como exitoso o processo de formação nacional apoiado não numa base racial homogênea, mas na constituição de uma cultura nacional, uma brasilidade mestiça, mas orgânica e unitária, pode ser lido como momento fundamental do movimento de "construção narrativa" da nação brasileira.

\section{A mestiçagem e a campanha da nacionalização}

A contestação do determinismo biológico reinante no âmbito dos debates sobre o futuro do Brasil até os anos 30 do séc. XX conforma o núcleo da defesa da mestiçagem feita por Freyre ${ }^{4}$. Freyre reconstrói o processo de constituição do Brasil desde o período colonial e mostra que a nação brasileira, a despeito da escravidão e da dizimação de povos indígenas, representa o encontro efetivo de três grupos humanos, os quais encontram-se numa relação de complementaridade entre si. Assim ter-se-ia constituído uma "brasileiridade" - unidade da diversidade -, no âmbito da qual cada um dos três grupos originais teria deixado uma contribuição relevante para a constituição do caráter nacional.

Graças à sua história, entre o ocidente e o oriente, a África, a Europa e a Ásia, os portugueses seriam portadores de três características fundamentais: miscibilidade, mobilidade e adaptabilidade climática. Para constituição da nação 
brasileira, a faculdade identificada por Freyre entre os portugueses de se fundirem biológica, social e culturalmente com outros povos teria desempenhado papel central. Conforme Freyre, os portugueses cultivavam uma predileção arquetípica pela mulher moura de pele morena, transferida automaticamente para a mulher indígena brasileira. Além disso, o colonizador português teria se empenhado em fazer do Brasil uma nação sem as fronteiras étnicas instransponíveis próprias a outras colônias, para o que se utilizou da língua portuguesa e da religião católica como referências unificadoras, destacando Freyre que a confissão católica representou durante muito tempo o único requisito para a admissão de novos imigrantes na colônia brasileira.

Do elemento indígena, Freyre destaca sobretudo a contribuição das índias, as quais teriam, ao lado de muitas especialidades culinárias, legado à cultura brasileira seu sentido de limpeza, sua disposição para o trabalho e sua estabilidade emocional. Do indígena do sexo masculino haveria, ao contrário, de se destacar antes de tudo as contribuições negativas, quais sejam, a indisciplina, a compulsividade e o desrespeito pela propriedade privada. Dos negros, Freyre ressalta a alegria vital, a flexibilidade e o "jogo de cintura", segundo ele, marcas inconfundíveis do caráter brasileiro.

Uma tal reconstrução da história de formação da sociedade brasileira traz consigo um conjunto variado de implicações políticas, as quais não se pode detalhar no corpo do presente trabalho. Destaca-se contudo três consequiências mais evidentes advindas das formulações de Freyre:

a) Desigualdade e problemas sociais, historicamente construídos, como o subjugo de determinados grupos como mulheres ou negros, são tratadas por Freyre como constitutivas de uma essência brasileira, infensas, portanto, à possibilidade de transformação.

b) A forma como a nação brasileira se constitui na região de Pernambuco é tratada por Freyre como representativa de todo o país, sem que seja verificada empiricamente a plausibilidade de tal extrapolação.

c) Como o modelo de Freyre supõe uma cultura unificada como fundamento da nação, restam limitados os espaços para a expressão de novas formas culturais, como aquelas trazidas pelos imigrantes que chegam ao país a partir da segunda metade do séc. XIX.

Essa "brasileiridade", monocultural em sua mesticidade, conforme Freyre a concebeu, encontra sua correspondência política mais perfeita na Campanha de nacionalização levada a efeito por Vargas a partir de 1937 e tendo à frente de sua concepção e sua implementação setores importantes das Forças Armadas. Com efeito, não parece exagerado traduzir o objetivo declarado da campanha de integrar culturalmente os imigrantes e seus descendentes como um esforço de abrasileiramento dos recém-chegados, a partir da concepção de brasilidade sintetizada por Freyre, àquela altura já dominante. Uma gama infindável de pronunciamentos e declarações esboçadas no âmbito da campanha de nacionalização varguista atesta a indignação contra os imigrantes e sobretudo seus descendentes que, supunha-se, descaracterizavam
${ }^{4}$ Como se sabe a questão se Freyre, de fato, se distancia do conceito de raça permanece aberta para seus intérpretes. Segundo a leitura de Araújo (1994), uma das interpretações mais completas e abrangentes da obra de Freyre, o autor de Casa-grande \& senzala apresenta uma visão neolamarquiana, segundo a qual o caráter humano deriva da combinação dos condicionantes socioculturais e climáticos. 
O abrasileiramento forçado dos descendentes de imigrantes apresenta um rasgo de enquadramento de gênero, ainda pouco focalizado na literatura. Seyferth (1997) destaca passagem do mesmo Bethlem, na qual ele mostra como as descendentes de alemães, ao compartilhar do lazer com os homens e podendo ser vistas publicamente em Blumenau até mesmo a tomar cerveja, violavam premissas essenciais da cultura brasileira. o direito de nacionalidade brasileiro, ao merecer o mesmo status de cidadania concernente aos demais brasileiros, sem se desfazer dos vínculos emocionais e culturais que os ligavam à pátria de seus antepassados. Ao lado do discurso nacionalista virulento, um conjunto não menos contundente de medidas repressivas compunha o arcabouço da campanha de nacionalização. Conforme já descrito, com muita ênfase e propriedade por autoras como Seyferth (1997, entre outros) e Fiori (1995, entre outros), tais ações policiais se voltavam, sobretudo, para aqueles campos que hoje se designaria por infra-estrutura comunicativa da sociedade civil, quais sejam, a escola, a vida associativa e a imprensa em outra língua que não o português.

Quando se compara os objetivos da Campanha de nacionalização com algumas passagens de Freyre fica evidente o quanto, a despeito das diferenças políticas entre Freyre e o governo getulista, o autor pernambucano compartilha do propósito maior de superação daquilo que à época se chama de quistos étnicos. Dessa forma, em publicação de 1939, o General Bethlem, responsável pela efetivação da Campanha no Vale do Itajaí, declarava:

Nós respeitamos os estrangeiros nos direitos que lhes asseguramos, por isso que são valiosos elementos de colaboração para nosso progresso. Mas nem porque os recebemos com a doçura do nosso temperamento; nem porque os acolhemos com a hospitalidade que é traço inconfundivel do nosso caráter, abrimos mão do direito que nos é fundamental como nação soberana, de orientar e dirigir a formação moral e cívica dos que nasceram no Brasil e brasileiros são (apud Seyferth, 1997, p. 107) 5 .

Paralelamente, em entrevista ao Diário de Pernambuco em 1942, Freyre afirmava:

No Brasil não deve haver lugar para racismos e outras ideologias anti-brasileiras. E aqui repito o que disse ao voltar, no começo de 1940, da minha primeira viagem ao Rio Grande do Sul e Santa Catharina: nesse sentido, a obra do Exército é efficiente e sympáthica. Seria absurdo admitirmos ao neo-brasileiro, o direito de florescer em grupos macissos ou compactos, à parte da cultura básica e essencial do Brasil e a do sentimento e fórmas christãs (Mello, 1942).

A campanha da nacionalização e as formulações coetâneas de Freyre deixam entrever uma curiosa inflexão nas formas de representação do país que se opera nos anos 40. A constituição de uma nação brasileira unitária, acima das diferenças étnicas, que ainda na política getulista representava um desiderato, um objetivo a ser alcançado, torna-se a partir de então, não mais prescrição mas descrição da nação, desde então, tratada como o amálgama exemplar de culturas 
e raças em plena sintonia e interpenetração. É exatamente essa imagem da nação que constitui o cerne do que se chamou acima de ideologia da mestiçagem a qual, a despeito das variações impostas pelos constrangimentos políticos próprios à cada época histórica, vige até pelo menos meados dos anos 70, preservando um núcleo de características inalteradas, a saber:

a) A intervenção estatal no campo da cultura baseia-se num conceito essencialista de brasilidade, através do qual algumas formas culturais são promovidas, enquanto outras manifestações, igualmente existentes, são sistematicamente desconsideradas.

b) Brasilidade se apresenta como uma identidade mestiça não étnica, capaz de assimilar todas as outras representações étnicas.

c) A idéia de raça é desqualificada enquanto instrumento dos discursos políticos públicos, ainda que continue orientando a ação e as hierarquizações estabelecidas pelos agentes sociais, cotidianamente. Assim, se constitui o mito da democracia racial, componente indispensável da ideologia da mestiçagem.

\section{Desenvolvimentos recentes e o fim da ideologia da mestiçagem}

$\mathrm{O}$ argumento que procura se desenvolver aqui e que, no presente contexto, só pode ser apresentado com o status de hipótese é que a mestiçagem, como ideologia de Estado, deixa de existir no Brasil contemporâneo, verificando-se que elementos essenciais desse construto político são crescentemente colocados em questão. Trata-se aqui da busca de novos canais de expressão de identidades culturais e da redescoberta de raízes étnicas, ofuscadas ou neutralizadas no período de vigência da ideologia da mestiçagem.

A observação das transformações no espaço público brasileiro nas últimas três décadas evidencia um processo de pluralização cultural e política expresso em desenvolvimentos muito variados, destacando-se entre esses: etnicização de muitas identidades políticas, vertiginoso crescimento do associativismo étnico, um novo direito indígena que pressupõe não mais uma paulatina assimilação dos grupos indígenas mas a permanente preservação de suas formas de vida. Detalhase três fenômenos particularmente representativos de tais transformações.

\section{Construção de uma etnia quilombola}

O termo quilombo possuía originalmente, como se sabe, um sentido preciso, servindo para definir as localidades formadas por negros que fugiam à escravidão e parecia até o final dos anos 80, para a maior parte dos brasileiros, um capítulo encerrado da história do país. Desde a introdução do discutido artigo 68 na constituição de 1988, o qual reconhece a figura dos remanescentes de quilombo, garantindo aos descendentes de escravos que habitam as terras dos antigos quilombos a propriedade do solo que ocupam, quilombo tornou-se um conceito em disputa, alvo de intermináveis refregas entre antropólogos, parlamentares e movimentos sociais. Algumas lideranças 
${ }^{6}$ Guimarães (2000), em programa de trabalho recente, indica a decodificação do florescimento recente dos traços culturais aqui tratado como etnização, a partir da idéia de raça, utilizando-a como categoria analítica. Percebe, portanto, a reconstrução dos três grupos "raciais" miticamente fundadores da nação - índio, negro, branco. Opta-se aqui por caracterizar tais processos como etnização ou reetnização por se entender que tal categoria, ainda que analiticamente frouxa, descreve mais adequadamente o ponto de partida das manifestações observadas contemporaneamente. Ou seja, a reidentificação dos índios não se dá através da categoria índio, mas pela pertença a uma etnia determinada. A reidentificação dos "brancos" não se dá igualmente pelo grupo de cor, mas pelo vínculo étnico correspondente. No caso dos afro-descendentes, a referência à raça, como se mostra abaixo, tem um sentido político, funcionando, por assim dizer, como substituto da pertença étnica. do Movimento Negro tentam estender o termo de tal sorte a tratar como quilombo todas aquelas comunidades rurais constituídas por uma parcela significativa de população negra. Para estas lideranças, trata-se de uma discussão política: a ampliação da definição deve permitir a correção das injustiças históricas e presentes cometidas contra a população negra (cf. Leite, 2000, p. 11s). Para o governo, em contrapartida, a questão é de ordem técnica e deve ser resolvida com base no cotejo de perícias antropológicas (sobre o papel dos laudos periciais, cf. NUER, 1996). O que chama atenção nas disputas políticas em torno da legalização das terras remanescentes de quilombos é a transformação dos quilombolas em etnia. Com efeito, se tomam-se os termos pelos quais A.D. Smith (cf. Hutchinson \& Smith, 1996) caracteriza uma etnia, quais sejam, a existência de um nome próprio comum, de um mito de uma ancestralidade compartilhada, de memórias históricas compartilhadas, de elementos de uma cultura comum, de um vínculo a um "homeland" e de um senso comum de solidariedade, fica evidente o acento étnico da política de reconhecimento dos quilombos. Nesse caso, pressupõem-se que, a despeito das diferenças regionais, as comunidades apresentem:

a) Marcas culturais particulares distintas daquilo que se entende como a cultura nacional hegemônica.

b) Vínculo histórico com um território.

c) Processos continuados de transmissão que assegurem a reprodução cultural do grupo.

Se admite-se que uma etnia quilombola através do concurso do Estado encontra-se em construção no Brasil, cai por terra um dos pressupostos fundamentais da ideologia da mestiçagem, já que em lugar de uma estratégia de assimilação vê-se operar uma política oficial de reconhecimento e mesmo promoção das diferenças culturais.

\section{Reintrodução do conceito raça no debate político}

O conceito raça apresenta uma carreira oscilante no Brasil. Se até os anos 30, tratava-se de um conceito fundado biologicamente e usado para hierarquizar os diferentes segmentos da população, verifica-se entre os anos 30 e 70 a perda de importância política do conceito. No âmbito do debate acadêmico, a idéia da existência biológica de raças entre seres humanos é também abandonada por completo. Seja com R. Bastide, seja com Florestan Fernandes ou F.H. Cardoso, as discussões sempre consideram a dimensão sociocultural e não mais a dimensão biológica das chamadas relações raciais (cf. Azevedo, 1964, p. 9; Guimarães, 1999, parte 2).

A partir dos anos 70, o conceito raça através, entre outros, da influência da discussão norte-americana, ganha renovada importância política no Brasil, funcionado como instrumento de ruptura da homogeneidade construída simbolicamente pela política da mestiçagem, como se se tratasse de dissociar os grupos socioculturais fundidos na simbologia da nação mestiça ${ }^{6}$. Assim, o conceito raça se transforma em instrumento de mobilização política, em cons- 
trução discursiva que deve fazer dos diferentes estratos populacionais afrodescendentes - do ponto de vista social e cultural tão diversos entre si - um coletivo político capaz de enfrentar as desigualdades raciais. A idéia de uma raça negra definida politicamente a partir de determinadas características corporais parece responder à impossibilidade fáctica de constituição de uma identidade propriamente étnica para o conjunto de afro-descendentes: além do processo de assimilação cultural no Brasil, o recrutamento forçado de escravos não considerava, obviamente, as fronteiras étnicas levando à constituição de grupos de população negra que reuniam pessoas portadoras de ascendência, tradições e traços culturais muito diversos.

Quando, nos finais dos anos 70, o movimento negro retoma o conceito raça com um sentido político, opera-se portanto uma inversão semântica fundamental na categoria usada historicamente para subjugar negros e outros não brancos. Não se trata, contudo, de um racismo invertido, como se grupos negros quisessem afirmar alguma distinção biológica essencial ou sua superioridade relativamente aos não negros. O que se tem é uma estratégia política de delimitação e mobilização dos grupos populacionais que, em virtude de um conjunto de características corporais, continua sistematicamente discriminado. Em muitos casos, pleiteia-se que aqueles grupos de pessoas que apresentam esse conjunto de características que historicamente conduziram à discriminação sejam agora recompensados pela introdução de mecanismos de correção das injustiças históricas e de obliteração do preconceito racial tão enraizado nas relações sociais (cf. Souza, 1997). Nessas disputas políticas, adquire papel central a construção de indicadores sociais que, ao distinguir a situação dos diferentes grupos de cor, revela o desfavorecimento sistemático dos grupos de pele escura, demonstrando, dessa forma, os limites da ideologia da mestiçagem, a qual prescrevia a justa recompensa dos méritos e esforços pessoais, independentemente de adscrições de qualquer ordem. Assim, a reabilitação contemporânea do conceito raça como instrumento de combate ao racismo fere de morte a ideologia que prometia, paradoxalmente, a proteção dos afro-descendentes contra a discriminação racial.

\section{Etnização de diferentes grupos socioculturais}

As estratégias de assimilação cultural associadas às políticas da mestiçagem puderam historicamente demonstrar sua eficácia. Em pouco mais de quatro décadas praticamente todos os grupos populacionais que viviam nas fronteiras territoriais brasileiras foram "integrados" na comunidade nacional através do sistema escolar unificado e da língua portuguesa. As diferenças culturais regionais não foram inteiramente apagadas, ao contrário, os tipos regionais - o vaqueiro nordestino, o gaúcho ou o seringueiro - foram sempre presença obrigatória nos livros escolares sendo realçados em linguagem folclorizada na literatura e na arte, como se representassem o testemunho vivo do caráter mestiço e plural da nação. As pertenças étnicas, contudo, vão lentamente desaparecendo por força das políticas assimilacionistas, do com- 
bate ao associativismo étnico, da eliminação da educação escolar em língua estrangeira e, como se mostrou, até mesmo através da perseguição política aberta dos que quisessem permanecer em sua condição de "estrangeiro". A exceção digna de nota aqui é representada por diferentes grupos indígenas que, a despeito de todas as dificuldades, mantiveram, graças à proteção legal e ao acesso difícil a suas reservas, suas formas de vida e muitos de seus traços culturais idiossincráticos. Alguns outros poucos grupos étnicos (pomeranos em Santa Catarina ou Espírito Santo), favorecidos normalmente pelo isolamento geográfico, puderam também permanecer infensos às estratégias assimilacionistas da mestiçagem, preservando, pelo menos em parte e fora do espaço público, sua especificidade lingüística e cultural.

A partir de finais dos anos 70 inicia-se todavia uma nova fase, caracterizada por uma efetiva busca de reconstrução de raízes culturais e étnicas por parte de variados grupos socioculturais. Entre os descendentes de alemães no sul do Brasil, por exemplo, observa-se o renascimento - insdistinguível da invenção - de festividades e tradições relacionadas com o país de origem de seus antepassados. Dessa forma, comemora-se desde 1984 na cidade de Blumenau, em Santa Catarina, a Oktoberfest, já transformada numa das maiores festas populares do Brasil (cf. Flores, 1997). Significativamente, os imigrantes alemães dirigidos para aquela região originalmente nada tinham que ver com a Bavária. A vigorosa festa bávara revelou, não obstante, apresentar o formato ideal para restaurar o orgulho e a economia blumenauense, depois da cidade ter sido duramente castigada por fortes enchentes. Na cidade de Pomerode, também localizada no Vale do Itajaí, verifica-se igualmente a busca da regermanização através da reintrodução do ensino do alemão nas escolas públicas do município e da tentativa da Prefeitura local de atrair turistas para a cidade, através da política voltada para marcar a origem germânica e para consolidar a imagem de Pomerode como "a cidade mais alemã do Brasil'. Fenômeno semelhante se dá naquelas regiões caracterizadas pela presença de japoneses ou italianos (cf. Mombelli, 1996).

Tais processos de reetnização marcam também a mobilização de grupos afro-descendentes em várias partes do país, ainda que aqui o catalisador da chamada reafricanização sejam os laços simbólicos que os unem a outras comunidades da diáspora africana (cf. Hanchard, 1996, p. 54s; cf. também Santos, 1999) e não a crença na existência de um resíduo do fundo cultural comum não obliterado pelas políticas de assimilação. Dessa forma, diferentemente de outros processos de reetnização, tais projetos identitários incorporam uma dimensão pós e transnacional, uma vez que não são as experiências coletivas e os significados culturais elaborados unicamente pelos afro-descendentes brasileiros que conformam as referências identitárias: "a reidentificação dos negros em termos étnicoculturais" se dá tanto a partir da "cultura afro-brasileira", como com base no "legado cultural e político do 'Atlântico Negro' - istoé, a renascença cultural caribenha, a luta contra o apartheid na África do Sul etc.” (Guimarães, 1995, p. 43). Até o momento, a busca da reafricanização nos termos acima mantém-se restrita a um 
grupo reduzido de afro-descendentes brasileiros, a maior parte desses define-se, em primeiro lugar, como brasileiro e não reconhece sua origem, nem mesmo remotamente, na África ${ }^{7}$. Ao mesmo tempo, as manifestações culturais trazidas à luz no bojo da reafricanização encontram grande ressonância, emprestando a tal fenômeno uma relevância política particular. Aênfase discursiva e estética da origem africana por parte dos movimentos sociais e de personalidades negras tem contribuído para fazer crescer a auto-estima dos afro-descendentes e fortalecê-los no combate cotidiano das situações de discriminação e racismo.

\section{Alguns desdobramentos teóricos}

A trajetória da ideologia da mestiçagem e, sobretudo, seu esgotamento, conforme sumariamente descrito acima, legam-nos um rico material para a reflexão teórica e para a avaliação política de suas consequiências.

Inicialmente, há que se registrar a dificuldade de decodificar os processos descritos com os instrumentos analíticos e as categorias teóricas da sociologia da cultura ou da sociologia política. O conceito hibridismo (com suas variações hibricidade, hibridação, etc.) aparece cada vez mais recorrentemente na literatura que discute as conseqüências culturais da globalização. Quando o conceito é deslocado, contudo, do sentido epistemológico e político relevante que lhe conferem os estudos pós-coloniais (cf. Costa, 2001) e transportado para a sociologia perde sua eficácia analítica e normativa. A categoria, ao descrever uma variedade imensa de processos simultâneos, sem permitir que se identifique as particularidades e especificidades que os distinguem apresenta pouca serventia para a ciência que se ocupa precisamente das diferenciações.

Ainda que num nível de elaboração teórica menos ambicioso que os estudos pós-coloniais, Garcia Canclini (1989), já pelo menos desde 1990, refere-se à América Latina como depositária de culturas híbridas. Isto é, desde a chegada dos portugueses ou espanhóis no continente, os processos culturais que têm lugar na América Latina seriam marcados pela diluição das fronteiras entre tradição e inovação, cultura erudita e cultura popular, marcas nativas e alienígenas. Na época contemporânea que ele qualifica de pós-moderna, tais processos teriam sido ainda mais acentuados, ainda que a hibridização corrente não seja mais traduzível numa grande narrativa de cunho emancipatório ou legitimador da dominação política, como era o caso na época moderna. O hibridismo caracterizaria hoje processos que não mais podem ser ordenados num mapa cognitivo ou lógico, nem se apresentam articulados internamente por seu sentido político. Não há neles atores, intenções ou coordenação, tratar-se-ia de movimentos difusos e dissociados. Do ponto de vista sociológico, trata-se, portanto, ao invés de um conceito de uma não-categoria que expressa a incapacidade de tradução analítica dos processos culturais vinculados à época contemporânea. De alguma maneira, o conceito é expressivo de uma certa postura epistemológica, orientada para a renúncia à decodificação dos fenômenos sociais através dos métodos e das categorias da sociologia.

\footnotetext{
${ }^{7}$ A primeira pesquisa abrangente sobre cor da pele e origem levada a efeito pelo IBGE revela que apenas $9,6 \%$ daqueles que são classificados oficialmente como negros reconhecem espontaneamente a origem africana. Entre os que são classificados como amarelos, em contrapartida, 70,8\% informam a origem japonesa (cf. Schwartzman, 1999).
} 
Para além da postura teórica que ele expressa e da qual aqui se pretende distanciar, há também razões de ordem estritamente analítica que confirmam a inutilidade do conceito de hibridização para os fins em tela. Os processos que ocorrem no contexto brasileiro contemporâneo são antes caracterizados pelo esforço de diferenciação e afirmação das particularidades culturais que pela fusão cultural. Trata-se do esforço político de separar as diversas partes daquilo que, na esteira de constituição da nação, se construiu como cultura nacional mestiça. Além disso, nos processos correntes de etnização tomam parte claramente atores com intenções e propósitos razoavelmente coerentes. Dessa forma, permanece tarefa dos cientistas sociais, em cada contexto particular, identificar a lógica e o sentido político das ações, diferenciando-as e traduzindo-as no vocabulário que distingue e qualifica o discurso científico.

Ao lado de sua face cultural, as transformações esboçadas apresentam também uma dimensão política evidente. Com efeito, na medida em que os processos de etnização assumem a forma de reivindicação por políticas públicas sensíveis à diferença, tratá-los sob a lente da ciência política e da teoria da democracia torna-se inadiável. É exatamente nessa interface que surgem dilemas acerca das medidas adequadas e justas para o tratamento de demandas não mais orientadas pelo ideal igualitário abstrato liberal, mas justificadas pelas necessidades culturais concretas de determinados grupos. Assume igual relevo nesse catálogo de questões as considerações acerca de quando mostra-se desejável a promoção e a proteção estatal de formas culturais de vida ameaçadas ou quando, ao contrário, a intervenção do Estado deve-se dirigir para a preservação da liberdade individual, eventualmente constrangida por uma eventual política identitária agressiva.

Esse tipo de questionamento, conforme mostrado em trabalho anterior (cf. Costa \& Werle, 2000), ocupou os cientistas sociais brasileiros nos anos 90, podendo-se já destacar dois grupos de posições e argumentos. Tratase, de um lado, da posição representada paradigmaticamente por Fábio W. Reis e de outro da defesa de uma política identitária, tratada aqui a partir dos argumentos de Antonio Sérgio Guimarães.

Para Reis (1997), a autonomia individual tem precedência sobre a autonomia coletiva, devendo o Estado se manter neutro relativamente às diferentes concepções do que é uma boa vida existentes na sociedade. Conforme o autor, o Estado não pode promover identidades culturais, deve, ao contrário, agir no sentido de constituição de uma democracia racial, na qual as características corporais ou as adscrições étnicas não tenham qualquer relevância distributiva. Isso não implica a impossibilidade de favorecimento preferencial de grupos sistematicamente prejudicados na ordem existente, tais compensações devem ser contudo temporárias e visam não promover uma identidade cultural coletiva, mas restabelecer uma igualdade efetiva de oportunidades. 
Guimarães, ao contrário, vê no princípio de igualdade liberal a causa do subjugo histórico dos não brancos. Na medida em que o tratamento igualitário preconizado pela constituição se distancia das relações sociais efetivamente dadas, a igualdade formal se transforma numa armadilha jurídico-ideológica que mina as possibilidades de resistência contra o racismo. $\mathrm{O}$ autor defende, por isso, uma intervenção estatal que promova a construção e consolidação de uma identidade negra, devendo-se reforçar, através de uma política de incentivos, a assunção pelos afro-descendentes da origem africana, de tal sorte que se crie uma sobreposição entre cor da pele e conformação étnica. Por esse meio, os grupos populacionais afro-descendentes deveriam ser encorajados a construir os laços de pertença desfeitos no curso da diáspora africana ou impedidos de se formar dada a vigência da política assimilacionista.

Quando se compara as posições de Reis e Guimarães, constata-se que ambas apresentam dificuldades. Ao distinguir estritamente entre o justo e o bom, portanto entre critérios de justiça e orientações culturais, Reis parece não levar adequadamente em conta a situação histórica de exclusão sistemática dos afro-descendentes. Dado um passado prolongado de injustiça e discriminação, a escolha da identidade cultural não pode ser considerada como questão pré-política, afeita exclusivamente à esfera pessoal. Parece caber nesse caso ao Estado a tarefa de promover determinadas formas culturais que a história da hegemonia branca desautorizou como primitivas e ultrapassadas, encorajando a pertença étnico-cultural. Não se trata, portanto, da preservação de direitos individuais, mas de políticas e direitos que, em face da ênfase cultural, só são aplicáveis a coletivos de pessoas (cf. Kymlicka, 1995).

A intervenção pública, contudo, não pode assumir o caráter propugnado por Guimarães. Em sua concepção, define-se a priori um modelo concreto de identidade a ser incentivado pelo Estado, desconsiderando a lição legada pelas correntes construtivistas, qual seja, a "identidade de um grupo não se define por um conjunto de fatos objetivos, ela é o produto de significados experenciados" (Young, 1995, p. 161; cf. também Benhabib, 1999, cap. 1). Traduzida para nossos termos, a perspectiva construtivista impõe a consideração de que as experiências coletivas de grupos excluídos conformam apenas um dos elementos determinantes de sua identidade, há que se perguntar antes de tudo sobre as formas de processamento simbólico de tais processos; qual é efetivamente o significado atribuído pelos envolvidos a esses elementos comuns que, virtualmente, conformam a identidade coletiva. No caso concreto dos afro-descendentes, parece que a maioria destes ainda percebe o princípio da democracia racial - tratado como ideal, objetivo a ser atingido, e não mais como um mito - como uma possibilidade efetiva de superação do preconceito racial. Como mostram alguns estudos de caso (cf. Sansone, 1996), boa parte dos afro-descendentes, quando confrontada com o racismo cotidiano, busca, informada pelo princípio liberal de igualdade, tornar real a democracia racial. Tais formas de confronto com o racismo deveriam ser 
desencorajadas, caso a enfática política da identidade de Guimarães fosse implementada. Por isso, parece que uma política sensível às diferenças não deve idealizar cenários de construção identitária possíveis, seu ponto de partida deveria ser os contextos e as formas efetivas dentro dos quais os diferentes grupos buscam o reconhecimento de suas diferenças.

Recebido para publicação em janeiro/2001

KEY WORDS: ethnicity, miscegenation, nationality, Brazil.
ABSTRACT: The image of a miscegenated, culturaly assimilationist and politically integrating Brazilianess delineates the heart of the ideology that constitutes the Brazilian nation, as of the first decades of the 20th century. The eulogy over hybridism was, thus, a means to overcome the racist biologisms that predominated in public and intellectual debates until then. However, such a nationality model increasingly lost its legitimizing strength during the process of democratization. Many of the recent cultural manifestations as well as many of the important social actors in Brazil nowadays look for an ethnic identification that will distinguish them from the nation that assimilated all the cultural differences. Thus, they express their discontent with structural inequalities associated to the process of the ideological construction of the mestizo nation. The paper describes such ethnizing processes and discusses their consequences for the democratic construction.

\section{REFERÊNCIAS BIBLIOGRÁFICAS}

Alencastro, Luís F. (1985) Geopolítica da mestiçagem. Novos Estudos, São Paulo, (11): 43-63, janeiro.

AraúJo, Ricardo B. (1994) Guerra e paz: Casa grande \& senzala e a obra de Gilberto Freyre nos anos 30. Rio Janeiro, Editora 34.

AzEvedo, Thales. (1964) Mestiçageme status no Brasil. Coimbra, Coimbra Graf.

BENHABIB, Seyla. (1999) Kulturelle Vielfalt und demokratische Gleichheit. Politische Partizipation im Zeitalter der Globalisierung. Frankfurt/M, Fischer, $121 \mathrm{p}$.

Bнавна, Homi. (1990) Dissemination: time, narrative and the margins of the modern nation. In: (org.). Nation and narration. London/ New York, Routledge, p. 291-322. 
Canclini, Nestor Garcia. (1989) Culturas hibridas: estratégias para entrar y salir de la modernidad. Mexico, Grijalbo.

Costa, Sérgio. (2001) Para além da nação: teoria social, cosmopolitismo e sociedades pós-nacionais. Novos Estudos, São Paulo, (59): 5-21, março.

\& Werle, Denilson L. (2000) Reconhecer as diferenças: liberais, comunitaristas e as relações raciais no Brasil. In: et alii. Cidadania e multiculturalismo. A teoria social no Brasil contemporâneo. Lisboa, Socius, p. 207-230.

FIORI, Neide. (1995) Homogeneidade cultural brasileira: estratégias governamentais sob o Estado Novo. In: Adorno, Sérgio (org.). A sociologia entre a modernidade e a contemporaneidade. Porto Alegre, Editora da Universidade, p. 209-226.

Fischlowitz, Estanislau. (1950) O século da questão racial. In: NASCIMENTo, A. et alii (org.). Relações de raça no Brasil. Rio de Janeiro, Quilombo, p. 57-65.

Flores, Maria Bernardete. (1997) Oktoberfest. Turismo, festa e cultura na estação do chopp. Florianópolis, Letras Contemporâneas.

FreYre, Gilberto. (1999) Casa-grande \& senzala. 1a edição 1933. São Paulo/Rio de Janeiro, Record.

GabBert, Wolfgang. (1993) Vom Land der Mestuzen zur multi-etnischen Nation: Staatspartei und Indianer im nachrevolutionären Mexiko. In: Dirmoser, Dietmar et alii (orgs.). Die Wilden und die Barbarei. Lateinamerika-Analyse und Berichte. Frankfurt, Lit, (16).

GuimarãEs, Antonio Sérgio. (1995) Racismo e anti-racismo no Brasil. Novos Estudos, São Paulo, (43): 26-44.

. (1999) Racismo e anti-racismo no Brasil. Rio de Janeiro, Editora 34. . (2000) Nacionalidade e novas identidades raciais no Brasil: uma hipótese de trabalho. São Paulo, manuscrito inédito.

Hanchard, Michael. (1996) Cinderela negra? Raça e esfera pública no Brasil. Estudos Afro-Asiáticos, Rio de Janeiro, (30): 41-59.

Hoffbauer, Andreas. (1995) Afro-brasilien: Vom 'weißen'Konzept zur schwarzen Kultur. Viena, Promedia.

Hutchinson, John \& Smith, Anthony. (1996) Ethnicity. Oxford, Oxford University Press.

KyMLicKA, Will. (1995) Multicultural citizenship. Oxford, Clarendon.

LeITE, Ilka B. (2000) Os quilombos no Brasil: questões conceituais e normativas. Textos e Debates NUER, Florianópolis, (7), 40p.

Mello, Arnon de. (1942) Entrevista. Diário de Pernambuco. 12/01. Disponível na Internet www.bvgf.fgf.org.br, Biblioteca virtual Gilberto Freyre . 
Mombelli, Raquel. (1996) Mi soi talian gracia a dio: Identidade étnica e separatismo no oeste catarinense. Florianópolis, Dissertação (Mestrado). Programa de Pós-Graduação em Antropologia Social da Universidade Federal de Santa Catarina.

Munanga, Kabengele. (1999) Rediscutindo a mestiçagem no Brasil. Identidade nacional versus identidade negra. Petrópolis, Vozes.

NUER. (1996) Laudos periciais antropológicos. Textos e debates NUER, Florianópolis.

ReIs, Fábio W. (1997) Mito e valor da democracia racial. In: SouzA, Jessé (org.). Multiculturalismo e racismo: uma comparação Brasil/EUA. Brasília, Paralelo 15, p. 221-231.

Rodrigues, Raimundo Nina. (1935) Os africanos no Brasil. 2a edição. São Paulo, Companhia Editora Nacional.

SAnsone, Lívio. (1996) As relações raciais em Casa-grande \& senzala revisitadas à luz do processo de internacionalização e globalização. In: Maio, Marcos C. \& SAntos, Ricardo V. (orgs.). Raça, ciência e sociedade. Rio de Janeiro, Fiocruz/CCBB, p. 207-218.

SANTOS, Jocélio T. (1999) Nação mestiça: discursos e práticas oficiais sobre os afro-brasileiros. Luso-Brazilian Review, Madison, 36(1): 19-31.

Schwarcz, Lilia. (1993) O espetáculo das raças. São Paulo, Companhia das Letras.

Schwartzman, Simon. (1999) Fora de foco: diversidade e identidades étnicas no Brasil. Novos Estudos, São Paulo, (55): 83-96.

SEYFERTH, Giralda. (1997) A assimilação dos imigrantes como questão nacional. Mana, Rio de Janeiro, 3(1): 95-131.

SouZA, Jessé. (1997) Multiculturalismo, racismo e democracia: por que comparar Brasil e Estados Unidos? In: (org.). Multiculturalismo e racismo: uma comparação Brasil/EUA. Brasília, Paralelo 15, p. 8-15.

SPECK, Bruno. (1999) Mestiçagem ou pluralismo étnico. Modelos de integração nacional no Brasil e no Peru. Mosaico, Vitória, 1(1): 83-106.

Ströbele-Gregor, Juliana. (1993) Vom indio zum mestizo... zum indio. In: Dirmoser, Dietmar et alii (orgs.). Die Wilden und die Barbarei. Lateinamerika - Analyse und Berichte. Frankfurt, Lit, (16), p.95112.

Vianna, Francisco J. Oliveira. (1933) Evolução do povo brasileiro. São Paulo.

YounG, Iris. (1995) Together in difference: transforming the logic of group political conflict. In: KYMLICKA, Will. (org.). The rights of minority cultures. New York/Oxford, Oxford University Press, p. 155-176. 